\title{
Investigating Computer Science Instructors Behavioral Intention to Adopt the Flipped Classroom Applying an Extended UTAUT Model: The Role of Age, Gender, and Experience
}

\author{
Eman M. Bakheet and Andrew M. Gravell
}

\begin{abstract}
The Flipped classroom has been applied widely in teaching computing courses. This paper aims to explore the impact of the moderating factors from the instructors' perspectives. The study presents the findings obtained from semi-structured interviews with fourteen flipped classroom practitioners. This article investigated three potential moderators, age, gender, and experience. The results show that age and gender do not have strong evidence on their impact on the factors that could influence the instructor's adoption decision. However, some indicators by practitioners refer to experience as a possible moderator that might have impacted the factors that could influence computer science instructors to adopt the flipped classroom.
\end{abstract}

Index Terms-Age, computer science instructors, experience, flipped classroom, gender, moderators, UTAUT.

\section{INTRODUCTION}

Many studies introduced, explained and shared their flipped classroom experience in computing courses. A flipped classroom definition, benefits and limitation were discussed in previously published work [1]. A literature review was conducted to understand how the flipped classroom was defined and applied in teaching computing courses.

Overall, reviewed studies were using the term inverted while others used flipped, however both led to the same approach. The flipped classroom was defined as a teaching approach divided into two main activities, in the class and out of the class.

In the in-class activities, the students play an essential role in being active member within the active learning environment. Then, out of the class activities is when students prepare for the learning materials before coming to class, with access to the material through online platforms or the learning management system.

A previously published work [1] explained the definition of the flipped classroom and listed the benefits and the limitations found in applying the flipped classroom in computing courses from the literature reviews.

Flipped classroom definition was reviewed from previous

Manuscript received March 11, 2021; revised July 5, 2021.

Eman M. Bakheet was with Saudi Electronic University. She is now with the School of Electronic and Computer Science, University of Southampton, UK (e-mail: E.M.Bakheet@ soton.ac.uk).

Andrew M. Gravell is with the School of Electronic and Computer Science, University of Southampton, Southampton, UK (e-mail: amg@ecs.soton.ac.uk). studies ([2]-[5], [6]-[12]), a combined definition was developed and is given in reference [1].

The summary of the discussed benefits and limitations are:

The discussed benefits are:

1) Improved final grades [7], [13]-[15]

2) Improved overall students' performance [2], [5], [13], [15]

3) Combined benefits of distance learning with collaborative learning [6], [8]

4) Enhanced positive attitudes [2], [16], [17]

The discussed limitations are:

1) Lack of student enjoyment [7], [12], [13]

2) Absenteeism by students [12], [17]

3) Gender difficulties and extra time required [12]

The article is structured as follows: Section II explained the mixed methods applied; Section III presents the findings and discussion; finally, Section IV presents the conclusion and future work.

\section{MiXed Method Research OR Methodological TRIANGULATION}

According to [18] Creswell (2009), the concept of mixed methods research was created in 1959. Reference [19] defined mixed methods research as "research in which the investigator collects and analyses data, integrates the findings and draws inferences using both qualitative and quantitative approaches or methods in a single study."

In order to organize the phases to be followed, this study adopts a sequential design for mixed-method research [18] (Creswell, (2009, p.211) to clarify what steps to follow. In the sequential or phased design of mixed-method research, either qualitative or quantitative data can be collected first in the data collection process. Therefore, the order relay on the researcher's needs. In this study, the sequential design is based on an exploratory strategy, which starts by collecting qualitative data to explore the factors affecting the educators' decisions. It then moves towards collecting quantitative data to gain a deeper understanding of these factors from a larger sample of participants.

Reference [20] compared structured questionnaires and semi-structured interviews. They firstly clarified that in structured questionnaires, data are collected from targeted participants through predetermined answers and then analyzed quantitatively. Semi-structured interviews move from general open-ended questions to more detailed questions 
that are then analyzed qualitatively. From the perspective of investigating educational assessment, questionnaires and interviews are usually used together in mixed methods research. In addition, [21] Cohen et al. (2007, p.143) confirm the role of methodological triangulation in educational research, noting that "methodological triangulation is the one used most frequently and the one that possibly has the most to offer".

\section{The QuAlitative STUDY}

The researcher aims in this article to investigate the factors moderators that could influence computer science instructors' decision to adopt or reject the flipped learning approach. A qualitative study with computer science flipped classroom practitioners was conducted. This article introduced the investigation conducted in the impact of the factors moderators: age, gender, and experience from three perspectives (teaching, flipped classroom, and learning management system).

This paper aims to answer the following question:

Could (Age, gender, and experience) have an impact on the five proposed factors?

Following an investigation to answer this query.

\section{Findings of the Qualitative Study}

First, the researcher started interviewing 14 flipped classroom practitioner who applied the flipped classroom approach in teaching their courses. Those practitioners were teaching mainly computing courses in addition to other related fields.

The following sections include the interviews' findings on the factors moderator's and their impact on the factors.

This study mainly focuses on three moderators:

1) Age

2) Gender

3) Experience including:
- Teaching experience

- Flipped classroom experience

- Learning management systems experience

In addition to confirming and validating the factors, the flipped classroom practitioners were also asked to rate the moderators such as age, gender, teaching experience, flipped classroom experience and learning management systems experience; to explore if each of those moderator's influences each of the proposed factors, which proposed in earlier work reference [22].

Responses from flipped classroom practitioners were varied, and some have not added comments in this section. Whereas some found it difficult to respond, responses that were collected from practitioners are divided based on the moderator and its influence on each of the five factors.

As a result, this section will be divided into five main sections: each discussing one of the five moderators and its influence on the five factors.

The five proposed factors are according to reference [22]:

- Performance expectancy (PE)

- Effort Expectancy (EE)

- Social Influence (SI)

- Facilitating Condition (FC)

- Technology self-efficacy (TSEF)

Those factors were discussed deeply in previous related work [22], in addition to previous work [23], which introduced the interviews process, methods to analyze the qualitative collected data, and findings of the qualitative data regarding the five proposed factors.

During the interview, participants were asked to discuss and rate whether each of the mentioned moderators would influence any of the five proposed factors. A five-point Likert scale was used [24] Likert (1932). starting from (1), which is highly disagree, to (5), which is highly agree.

A. Age

TABLE I: SUMMARIZES 14 PARTICIPANTS' RESPONSES ON THE INFLUENCE OF AGE ON THE FIVE FACTORS

\begin{tabular}{|c|c|c|c|c|c|c|c|c|c|c|c|c|c|c|c|c|c|c|c|c|c|c|c|c|c|}
\hline & \multicolumn{25}{|c|}{ Age } \\
\hline Factors & \multicolumn{5}{|c|}{ PE } & \multicolumn{5}{|c|}{ EE } & \multicolumn{5}{|c|}{ SI } & \multicolumn{5}{|c|}{ FC } & \multicolumn{5}{|c|}{ TSEF } \\
\hline Scale & 5 & 4 & 3 & 2 & 1 & 5 & 4 & 3 & 2 & 1 & 5 & 4 & 3 & 2 & 1 & 5 & 4 & 3 & 2 & 1 & 5 & 4 & 3 & 2 & 1 \\
\hline FC-P1 & & & 1 & & & & & & 1 & & & & & & & & & & & & & & & & \\
\hline FC-P2 & & & 1 & & & & & 1 & & & & & 1 & & & & & 1 & & & & & 1 & & \\
\hline FC-P3 & & & & 1 & & & & & 1 & & & 1 & & & & & & & 1 & & & & & 1 & \\
\hline FC-P4 & & & & 1 & & & & & 1 & & & & & 1 & & & & & 1 & & & 1 & & & \\
\hline FC-P5 & & & & 1 & & & 1 & & & & & & & & & & & & & & & & & 1 & \\
\hline FC-P6 & & & & & & & & & & & & & & & & & & & & & & & & & \\
\hline FC-P7 & & & & 1 & & & & & 1 & & & & & 1 & & & & & 1 & & & & & 1 & \\
\hline FC-P8 & & & & & & & & 1 & & & & & & & & & & & & & & 1 & & & \\
\hline FC-P9 & & & & & & & & & & & & & & & & & & & & & & & & & \\
\hline FC-P10 & & & & & & & 1 & & & & & & & & & & & & & & & 1 & & & \\
\hline FC-P11 & & & & & & & & & & & & 1 & & & & & & & & & & & & & \\
\hline FC-P12 & & & 1 & & & & & & & & & & & & & & & & & & & & & & \\
\hline FC-P13 & & 1 & & & & & 1 & & & & & & & & & & & & & & & & & & \\
\hline FC-P14 & & & & 1 & & & & & 1 & & & & & 1 & & & & & 1 & & & & & 1 & \\
\hline Total & 0 & 1 & 3 & 5 & 0 & 0 & 3 & 2 & 5 & 0 & 0 & 2 & 1 & 3 & 0 & 0 & 0 & 1 & 4 & 0 & 0 & 3 & 1 & 4 & 0 \\
\hline
\end{tabular}


In general, flipped practitioners $(2,4$, and 14) commented that they believe that age does not have an impact on the factors. FC-P2 stated that "In my view, age does not matter, at any age one can adopt flipped classroom if associated with teaching faculty".

However, flipped practitioners (1, 5, 13, 8, and 12) commented on the possibilities of age impact. Some comments combined the influence of both age and the experience of the instructors in teaching.

Flipped practitioners (1, and 12) shared thoughts that more advanced instructors might not be able to adopt flipped classroom easily. Where FC-P1 commented, "I think age may be a factor, if someone is more advanced in their career they might not like be willing to kind of trade-off the effort that it takes to make a flipped classroom for you know what it's going to help them in terms of their job performance". Additionally, FC-P12 commented, "I think in general; you would find that younger instructors would potentially be more open to flipped classroom. You know older staff have been doing things for a number of years. They feel that they found a way that works for them and they need to be persuaded more to adopt. It's a big generalization".

Besides, flipped practitioners (5, and 13) commented on how experience in teaching could have impact on age. FC-P5 commented, "Experience could correlate with age", adding "I've been teaching maybe six - seven years only. So my colleagues and we were really enthusiastic about this one. But my colleagues who have been successfully teaching for 20 to 30 years they might not be quite that enthusiastic. So I would say experience in traditional methods might be a negative factor".

However, FC-P13 commented that, "Age and experience can influence performance expectancy, I've been in education for over 30 years. So I feel I'm very comfortable with the material. And this this is necessary because you see when you're lecturing in a more traditional way, you have your course prepared, these are the examples I'm going to do, and so on. It's a very predictable. This environment, flipped classroom is much less predictable, so you really have to feel comfortable with the material, and to be able to handle that like Whatever comes your way you have to be able to handle that".

While FC-P8 stated that, in terms of creating online content, it might be, "in terms of creating the online content then there may be an age difference because it might be that much younger instructors might find it easier to find and use a lot of tools that help to make the online content".

\section{B. Gender}

Participants in general, disagreed that Gender could have an influence over the factors. Some participants gave a clear statement of their disagreement with this concept, flipped practitioners $(1,2,4,10,13$, and 14). FC-P1 commented, "I don't see how gender would affect it at all or make a difference". FC-P2 added, "In my view gender also does not matter". Whereas FC-P8 specified that probably there is a gender difference in the effort expectancy factor, stating that "there might be a gender difference in efforts expectancy".

However, two participants, FC-P5, and FC-P12 did not provide comments on Gender, both stating they had no experience on which to base an opinion.

While FC-P11 provide a strong disagreement with the gender impact on the factors, commenting: "Definitely highly disagree with all”.

TABLE II: SUMMARIZES 14 PARTICIPANTS’ RESPONSES ON THE INFLUENCE OF GENDER ON THE FIVE FACTORS

\begin{tabular}{|c|c|c|c|c|c|c|c|c|c|c|c|c|c|c|c|c|c|c|c|c|c|c|c|c|c|}
\hline \multirow{3}{*}{$\begin{array}{l}\text { Factors } \\
\text { Scale }\end{array}$} & \multicolumn{25}{|c|}{ Gender } \\
\hline & \multicolumn{5}{|c|}{ PE } & \multicolumn{5}{|c|}{ EE } & \multicolumn{5}{|c|}{ SI } & \multicolumn{5}{|c|}{ FC } & \multicolumn{5}{|c|}{ TSEF } \\
\hline & 5 & 4 & 3 & 2 & 1 & 5 & 4 & 3 & 2 & 1 & 5 & 4 & 3 & 2 & 1 & 5 & 4 & 3 & 2 & 1 & 5 & 4 & 3 & 2 & 1 \\
\hline FC-P1 & & & & & 1 & & & & 1 & & & & & & & & & & & & & & & & \\
\hline FC-P2 & & & 1 & & & & & 1 & & & & & 1 & & & & & 1 & & & & & 1 & & \\
\hline FC-P3 & & & & & 1 & & & & & 1 & & 1 & & & & & & & & 1 & & 1 & & & \\
\hline FC-P4 & & & & 1 & & & & & 1 & & & & & 1 & & & & & 1 & & & & & 1 & \\
\hline FC-P5 & & & & & & & & & & & & & & & & & & & & & & & & & \\
\hline FC-P6 & & & & & & & & & & & & & & & & & & & & & & & & & \\
\hline FC-P7 & & & & 1 & & & & & 1 & & & & & 1 & & & & & 1 & & & & & 1 & \\
\hline FC-P8 & & & & & & & & 1 & & & & 1 & & & & & & & & & & & & & \\
\hline FC-P9 & & & & & & & & & & & & & & & & & & & & & & & & & \\
\hline FC-P10 & & & & 1 & & & & & 1 & & & & & 1 & & & & & 1 & & & & & 1 & \\
\hline FC-P11 & & & & & 1 & & & & & 1 & & & & & 1 & & & & & 1 & & & & & 1 \\
\hline FC-P12 & & & & & & & & & & & & & & & & & & & & & & & & & \\
\hline FC-P13 & & & & 1 & & & & & 1 & & & & & & & & & & & & & & & & \\
\hline FC-P14 & & 1 & & & & & & 1 & & & & 1 & & & & & & 1 & & & & & 1 & & \\
\hline Total & 0 & 1 & 1 & 4 & 3 & 0 & 0 & 3 & 5 & 2 & 0 & 3 & 1 & 3 & 1 & 0 & 0 & 2 & 3 & 2 & 0 & 1 & 2 & 3 & 1 \\
\hline
\end{tabular}




\section{Teaching Experience}

In terms of the impact of the teaching experience on the five factors, flipped classroom practitioners provide varied responses. Flipped practitioners (2, 12, 3, 4, 5, and 13), commented on the relationship between longer experience in teaching in facilitating aspects of the adoption, FC-P2 stated that "teaching experience strongly influences all the factors in a positive way. Experience makes perfection and leads to make positive impact". Additionally, FC-P12 commented, "I think you would say that more experienced people would be a positive correlation. How strong it is, I'm not sure, but there is some correlation". FC-P3 added, "I think the more experienced somebody has the more confident they're going to feel". PC-P5 commented that experience in teaching could reduce the effort, "probably, the experience will reduce the effort spent. Because I know that very experienced those senior teachers they can very easily create good lectures, like lecture topics, for example create like sensible assignments".

Whereas, in terms of the performance expectancy and experience with the materials, FC-P13 provided an explanation and recommendations on when it is suitable to apply the flipped classroom in the teaching, "not recommended to do flipped classroom for new lecturer who have no experience. I don't think I would recommend, for instance if a graduate student, PhD student is assigned to teach a course, I would not recommend the flipped classroom for the first time they teach that course. I would say teach it once or twice that you get more familiar with the content of the course, and then experiment more with the flipped classroom.".

FC-Ps (13 and 4) provide similar thoughts in regards of effort expectancy. FC-P13 commented, “if you're more experienced or whatever class you teach in whatever format, you're going to be better prepared to spend less time designing the classes and preparing". FC-P4 stated that less experienced staff "might struggle more, to find the answer to their questions rather than those who already work for many years and teaching and can easily answer any questions of students".

Also, FC-P4 commented, "if you are experienced you don't spend the time to re-watch those videos. For those who are not experienced they have to spend the time on re-watching videos, maybe re-do the exercises. Even the new exercise which then use in the lab, they still probably need to solve them before giving to the student. And so it definitely takes more time than those who are very experienced in teaching". FC-P11 added, "the more experience you've got, the more the bigger your network and the more people that you interact with probably on average to influence you".

TABLE III: SUMMARIZES 14 PARTICIPANTS' RESPONSES ON THE INFLUENCE OF TEACHING EXPERIENCE ON THE FIVE FACTORS

\begin{tabular}{|c|c|c|c|c|c|c|c|c|c|c|c|c|c|c|c|c|c|c|c|c|c|c|c|c|c|}
\hline \multirow{2}{*}{ Factors } & \multicolumn{25}{|c|}{ Teaching experience } \\
\hline & \multicolumn{5}{|c|}{ PE } & \multicolumn{5}{|c|}{$\mathbf{E E}$} & \multicolumn{5}{|c|}{ SI } & \multicolumn{5}{|c|}{ FC } & \multicolumn{5}{|c|}{ TSEF } \\
\hline Scale & 5 & 4 & 3 & 2 & 1 & 5 & 4 & 3 & 2 & 1 & 5 & 4 & 3 & 2 & 1 & 5 & 4 & 3 & 2 & 1 & 5 & 4 & 3 & 2 & 1 \\
\hline FC-P1 & & & 1 & & & & & & 1 & & & & & & & & & & & & & & & & \\
\hline FC-P2 & 1 & & & & & 1 & & & & & 1 & & & & & 1 & & & & & 1 & & & & \\
\hline FC-P3 & & 1 & & & & & 1 & & & & & & & & & & 1 & & & & & 1 & & & \\
\hline FC-P4 & 1 & & & & & 1 & & & & & & & & & & & & & & & & & & & \\
\hline FC-P5 & & & & & & & & & & & & & & & & & & & & & & & & & \\
\hline FC-P6 & & & & & & & & & & & & & & & & & & & & & & & & & \\
\hline FC-P7 & & 1 & & & & & 1 & & & & & & & 1 & & & 1 & & & & & 1 & & & \\
\hline FC-P8 & & 1 & & & & & & & & & & & & & & & 1 & & & & & 1 & & & \\
\hline FC-P9 & & & & & & & & & & & & & & & & & & & & & & & & & \\
\hline FC-P10 & 1 & & & & & & & & & & & & & & & & & & & & & & & & \\
\hline FC-P11 & & & & & 1 & & 1 & & & & & 1 & & & & & & & & 1 & & 1 & & & \\
\hline FC-P12 & & & 1 & & & & & & & & & & & & & & & & & & & & & & \\
\hline FC-P13 & 1 & & & & & 1 & & & & & 1 & & & & & 1 & & & & & 1 & & & & \\
\hline FC-P14 & & 1 & & & & & 1 & & & & & & 1 & & & & & 1 & & & & & 1 & & \\
\hline Total & 4 & 4 & 2 & 0 & 1 & 3 & 4 & 0 & 1 & 0 & 2 & 1 & 1 & 1 & 0 & 2 & 3 & 1 & 0 & 1 & 2 & 4 & 1 & 0 & 0 \\
\hline
\end{tabular}




\section{Flipped Classroom Experience}

Overall some participants rated how flipped classroom experience would influence the five factors. Indeed, FC-P1 commented that "Maybe I could see it go both ways because someone who does have experience in flipping a classroom they might have had a bad experience or they might have realized that it's a lot of work and you know and it may not be willing to do that again".

Additionally, FC-P2 stated, "Flipped classroom experience would help in learning and making out ways to deliver in a refined way and making positive impact on all factors in long run". While FC-P11 specified experience "could increase your self-efficacy because you've done it".

TABLE IV: SUMMARIZES 14 PARTICIPANTS’ RESPONSES ON THE INFLUENCE OF FLIPPED CLASSROOM EXPERIENCE ON THE FIVE FACTORS

\begin{tabular}{|c|c|c|c|c|c|c|c|c|c|c|c|c|c|c|c|c|c|c|c|c|c|c|c|c|c|}
\hline & \multicolumn{25}{|c|}{ Flipped classroom experience } \\
\hline Factors & \multicolumn{5}{|c|}{ PE } & \multicolumn{5}{|c|}{ EE } & \multicolumn{5}{|c|}{ SI } & \multicolumn{5}{|c|}{ FC } & \multicolumn{5}{|c|}{ TSEF } \\
\hline Scale & 5 & 4 & 3 & 2 & 1 & 5 & 4 & 3 & 2 & 1 & 5 & 4 & 3 & 2 & 1 & 5 & 4 & 3 & 2 & 1 & 5 & 4 & 3 & 2 & 1 \\
\hline FC-P1 & & & 1 & & & & & & 1 & & & & & & & & & & & & & & & & \\
\hline FC-P2 & 1 & & & & & 1 & & & & & 1 & & & & & 1 & & & & & 1 & & & & \\
\hline FC-P3 & & 1 & & & & & 1 & & & & & & & & & & & & & & & 1 & & & \\
\hline FC-P4 & 1 & & & & & & & & & & & & 1 & & & 1 & & & & & 1 & & & & \\
\hline FC-P5 & & 1 & & & & & & & 1 & & & & & & & & & & & & & 1 & & & \\
\hline FC-P6 & & & & & & & & & & & & & & & & & & & & & & & & & \\
\hline FC-P7 & & 1 & & & & & 1 & & & & & & & 1 & & & 1 & & & & & 1 & & & \\
\hline FC-P8 & & 1 & & & & & 1 & & & & & & & & & & & & & & & & & & \\
\hline FC-P9 & & & & & & & & & & & & & & & & & & & & & & & & & \\
\hline FC-P10 & 1 & & & & & & & & & & & & & & & & & & & & & 1 & & & \\
\hline FC-P11 & 1 & & & & & 1 & & & & & & & & & 1 & 1 & & & & & 1 & & & & \\
\hline FC-P12 & & & & & & & & & & & & & & & & & & & & & & & & & \\
\hline FC-P13 & & 1 & & & & & 1 & & & & & & 1 & & & & 1 & & & & & 1 & & & \\
\hline FC-P14 & & 1 & & & & & 1 & & & & & 1 & & & & & 1 & & & & & 1 & & & \\
\hline Total & 4 & 6 & 1 & 0 & 0 & 2 & 5 & 0 & 2 & 0 & 1 & 1 & 2 & 1 & 1 & 3 & 3 & 0 & 0 & 0 & 3 & 6 & 0 & 0 & 0 \\
\hline
\end{tabular}

\section{E. Learning Management System Experience}

Participants provided varied responses. FC-P1 commented, "the learning management system I used was one that I used anyway. I mean we use it anyway for other courses and it did not particularly help me or hinder like it didn't get in the way of flipping the classroom". In addition, FC-P13, who rated it as least significant, said, "I think this one has the least, from my perspective, the least significant".

Indeed, FC-P3 commented on the existence of an influence on the technology self-efficacy, "Probably well certainly technological self-efficacy there's an influence there. To the extent that learning management systems might encourage people to do sort of some flipped instruction that might influence performance expectation".

While FC-P11 gave strong agreement on the influence of LMS experience on three proposed factors as follow: the effort expectancy, facilitating conditions, and technology self-efficacy.

FC-P11 commented in terms of the LMS influence performance expectancy, "I think if you've got an LMS experience that could influence your performance, because just you've seen it". And, in terms of LMS influence effort expectancy, added, "In that case, I would say very agree, because the effort is actually directly related to using the resource, which is a little bit different from the performance.
As well as in terms of influence of LMS on facilitating conditions and technology self-efficacy, well that's definitely a relationship is there. Because if you've used the LMS a lot, you'd know more about the infrastructure and how it works"

In terms of the factors moderators that may influence the adoption decision by computer science instructors, based on the collected data, see (Table VII) for more details in the received responses.

Based on the collected data from flipped classroom practitioners, the factors moderators grouped into two main sections:

1) The majority of practitioners emphasized that age and gender do not have influence see (table VII). The majority of responses disagreed with the impact.

2) However, the experience had different indicators by the flipped classroom practitioners.

Overall, the experience divided into three primary perspectives: teaching experience, flipped classroom experience and learning management systems usage experience.

- Teaching experience results show that it might have an influence on some factors (PE, EE, TSEF).

- Also, the flipped classroom experience is suggested to have an influence on (PE, EE, FC, TSEF) factors.

- Finally, learning management systems experience is suggested to have an influence on the (EE) factor. 
TABLE V: SUMMARIZES 14 PARTICIPANTS' RESPONSES ON THE INFLUENCE OF LMS EXPERIENCE ON THE FIVE FACTORS

\begin{tabular}{|c|c|c|c|c|c|c|c|c|c|c|c|c|c|c|c|c|c|c|c|c|c|c|c|c|c|}
\hline & \multicolumn{25}{|c|}{ LMS experience } \\
\hline Factors & \multicolumn{5}{|c|}{ PE } & \multicolumn{5}{|c|}{$\mathbf{E E}$} & \multicolumn{5}{|c|}{ SI } & \multicolumn{5}{|c|}{ FC } & \multicolumn{5}{|c|}{ TSEF } \\
\hline Scale & 5 & 4 & 3 & 2 & 1 & 5 & 4 & 3 & 2 & 1 & 5 & 4 & 3 & 2 & 1 & 5 & 4 & 3 & 2 & 1 & 5 & 4 & 3 & 2 & 1 \\
\hline FC-P1 & & & & 1 & & & & & 1 & & & & & & & & & & & & & & & & \\
\hline FC-P2 & & & & & & & & & & & & & & & & & & & & & & & & & \\
\hline FC-P3 & & 1 & & & & & & & & & & & & & & & & & & & & 1 & & & \\
\hline FC-P4 & & & & & 1 & & & & & 1 & & & & & 1 & & & & & 1 & & & & & 1 \\
\hline FC-P5 & & 1 & & & & & 1 & & & & & & & & & & & & & & & 1 & & & \\
\hline FC-P6 & & & & & & & & & & & & & & & & & & & & & & & & & \\
\hline $\begin{array}{l}\text { FC-P7 } \\
\end{array}$ & & 1 & & & & & 1 & & & & & & & 1 & & & 1 & & & & & 1 & & & \\
\hline FC-P8 & & 1 & & & & & 1 & & & & & & & & & & & & & & & & & & \\
\hline FC-P9 & & & & & & & & & & & & & & & & & & & & & & & & & \\
\hline FC-P10 & & & & & & & 1 & & & & & & & & & & & & & & & & & & \\
\hline FC-P11 & & 1 & & & & 1 & & & & & & & & & 1 & 1 & & & & & 1 & & & & \\
\hline FC-P12 & & & & & & & & & & & & & & & & & & & & & & & & & \\
\hline FC-P13 & & & 1 & & & & & 1 & & & & & 1 & & & & & 1 & & & & & 1 & & \\
\hline FC-P14 & & & 1 & & & & 1 & & & & & & 1 & & & 1 & & & & & 1 & & & & \\
\hline Total & 0 & 5 & 2 & 1 & 1 & 1 & 5 & 1 & 1 & 1 & 0 & 0 & 2 & 1 & 2 & 2 & 1 & 1 & 0 & 1 & 2 & 3 & 1 & 0 & 1 \\
\hline
\end{tabular}

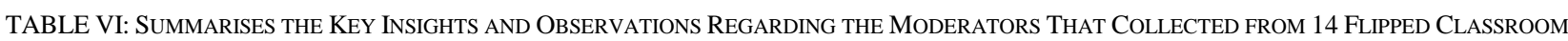
PRACTITIONERS

\begin{tabular}{|c|c|c|c|}
\hline Moderators impact on the factors & \# Agreement & \# Neutral & \# Disagreement \\
\hline \multicolumn{4}{|c|}{ Age } \\
\hline Performance Expectancy (PE) & 1 & 3 & 5 \\
\hline Effort Expectancy (EE) & 3 & 2 & 5 \\
\hline Social Influence (SI) & 2 & 1 & 3 \\
\hline Facilitating Condition (FC) & 0 & 1 & 4 \\
\hline Technology Self-Efficacy (TSEF) & 3 & 1 & 4 \\
\hline \multicolumn{4}{|c|}{ Gender } \\
\hline Performance Expectancy (PE) & 1 & 1 & 7 \\
\hline Effort Expectancy (EE) & 0 & 3 & 7 \\
\hline Social Influence (SI) & 3 & 1 & 4 \\
\hline Facilitating Condition (FC) & 0 & 2 & 5 \\
\hline Technology Self-Efficacy (TSEF) & 1 & 2 & 4 \\
\hline \multicolumn{4}{|c|}{ Teaching experience } \\
\hline Performance Expectancy (PE) & 8 & 2 & 1 \\
\hline Effort Expectancy (EE) & 7 & 0 & 1 \\
\hline Social Influence (SI) & 3 & 1 & 1 \\
\hline Facilitating Condition (FC) & 5 & 1 & 1 \\
\hline Technology Self-Efficacy (TSEF) & 6 & 1 & 0 \\
\hline \multicolumn{4}{|c|}{ Flipped classroom experience } \\
\hline Performance Expectancy (PE) & 10 & 1 & 0 \\
\hline Effort Expectancy (EE) & 7 & 0 & 2 \\
\hline Social Influence (SI) & 2 & 2 & 2 \\
\hline Facilitating Condition (FC) & 6 & 0 & 0 \\
\hline Technology Self-Efficacy (TSEF) & 9 & 0 & 0 \\
\hline \multicolumn{4}{|c|}{ Learning management system experience } \\
\hline Performance Expectancy (PE) & 5 & 2 & 2 \\
\hline Effort Expectancy (EE) & 6 & 1 & 2 \\
\hline Social Influence (SI) & 0 & 2 & 3 \\
\hline Facilitating Condition (FC) & 3 & 1 & 1 \\
\hline Technology Self-Efficacy (TSEF) & 5 & 1 & 1 \\
\hline
\end{tabular}

\section{CONCLUSION AND FutURE WORK}

This paper provides an extended investigation of the factors moderators, which are age, gender, and experience.

The introduction provides insights into the accomplished contributions in the flipped classrooms, such as the advantages, the limitations, and comparing between flipped and traditional teaching approach in computing courses.

This paper provides the preliminary findings of an investigation of three factors moderators with flipped classroom practitioners who have applied the flipped classroom in their teaching. A total of fourteen semi-structured interviews have been conducted. 
Findings show that age and gender do not have strong evidence on their impact on the factors that could influence the instructor's adoption decision. However, some indicators by practitioners refer to experience as a possible moderator that might have impacted the factors that could influence computer science instructors to adopt the flipped classroom.

The researcher aims to continue to study the factors that could influence the computer science instructors' adoption decision of the flipped learning approach. Then as future work, a quantitative study with computer science flipped classroom practitioners from a global perspective will be conducted.

\section{CONFLICT OF INTEREST}

"The authors declare no conflict of interest".

\section{AUTHOR CONTRIBUTIONS}

Eman M. Bakheet conducted the research, analyzed the data, wrote the paper; Andrew M Gravell reviewed the work; all authors had approved the final version.

\section{ACKNOWLEDGMENT}

My sincere thanks to all flipped classroom practitioners who took part in this study and provided me with insights and information based on their valuable experience. My sincere thanks to Saudi Electronic University for its sponsorship.

\section{REFERENCES}

[1] E. M. Bakheet and G. A. M. Gravell, "Would flipped classroom be my approach in teaching computing courses: Literature review," in Proc. 2021 9th International Conference on Information and Education Technology (ICIET), IEEE. pp. 166-170.

[2] J. A. Day and J. D. Foley, "Evaluating a web lecture intervention in a human-computer interaction course," IEEE Transactions on Education, vol. 49, no. 4, pp. 420-431, 2006.

[3] V. Singh, S. Abdellahi, M. L. Maher, and C. Latulipe, "The video collaboratory as a learning environment," in Proc. the 47th ACM Technical Symposium on Computing Science Education, 2016, pp. 352-357.

[4] M. L. Maher, C. Latulipe, H. Lipford, and A. Rorrer, "Flipped classroom strategies for CS education," in Proc. the 46th ACM Technical Symposium on Computer Science Education, 2015, pp. 218-223.

[5] C. Latulipe, A. Rorrer, and B. Long, "Longitudinal data on flipped class effects on performance in cs1 and retention after cs1," in Proc. the 49th ACM Technical Symposium on Computer Science Education, 2018, pp. 411-416.

[6] G. Gannod, J. Burge, and M. Helmick, "Using the inverted classroom to teach software engineering," in Proc. 2008 ACM/IEEE 30th International Conference on Software Engineering, 2008, IEEE, pp. 777-786.

[7] D. Horton, M. Craig, J. Campbell, P. Gries, and D. Zingaro, "Comparing outcomes in inverted and traditional CS1," in Proc. the 2014 Conference on Innovation \& Technology in Computer Science Education, 2014, pp. 261-266.

[8] V. Dolgopolovas, L. Savulionienè, and V. Dagienè, "Enhancing students' motivation in the inverted CS2 course: A case study," in Proc the International Conference on e-Learning 2014, 2014: Education, Audiovisual and Culture Executive Agency Tenerife, Spain, pp. 137-141.

[9] S. L. Dazo, N. R. Stepanek, R. Fulkerson, and B. Dorn, "An empirical analysis of video viewing behaviors in flipped CS1 courses," ACM Inroads, vol. 7, no. 4, pp. 99-105, 2016.

[10] C. Latulipe, N. B. Long, and C. E. Seminario, "Structuring flipped classes with lightweight teams and gamification," in Proc. the 46th ACM Technical Symposium on Computer Science Education, 2015, pp. 392-397.

[11] Y. Yang, H. Wu, and J. Cao, "Smartlearn: Predicting learning performance and discovering smart learning strategies in flipped classroom," in Proc. 2016 International Conference on Orange Technologies (ICOT), 2016, IEEE, pp. 92-95.

[12] J. Campbell, D. Horton, M. Craig, and P. Gries, "Evaluating an inverted CS1," in Proc. the 45th ACM Technical Symposium on Computer Science Education, 2014, pp. 307-312.

[13] A. Amresh et al., "Evaluating the effectiveness of flipped classrooms for teaching CS1," in Proc. 2013 IEEE Frontiers in Education Conference (FIE), 2013, IEEE, pp. 733-735.

[14] J. Elmaleh and V. Shankararaman, "Improving student learning in an introductory programming course using flipped classroom and competency framework," in Proc. 2017 IEEE Global Engineering Education Conference (EDUCON), 2017, IEEE, pp. 49-55.

[15] J. Campbell, D. Horton, and M. Craig, "Factors for success in online CS1," in Proc. the 2016 ACM Conference on Innovation and Technology in Computer Science Education, 2016, pp. 320-325.

[16] A. Knutas, A. Herala, E. Vanhala, and J. Ikonen, "The flipped classroom method: Lessons learned from flipping two programming courses," in Proc. the 17th International Conference on Computer Systems and Technologies 2016, 2016, pp. 423-430.

[17] M. N. Giannakos et al., "Reviewing the flipped classroom research: reflections for computer science education," in Proc. the Computer Science Education Research Conference, 2014, pp. 23-29.

[18] J. Creswell, Reserach Design-Qualitative, Quantitative, and Mixed Methods Approaches 6th Printing 2012, New Delhi: Vivek Mehara SAGE Publications India Pvt Ltd., 2009.

[19] L. Doyle, A.-M. Brady, and G. Byrne, "An overview of mixed methods research," Journal of Research in Nursing, vol. 14, no. 2, pp. 175-185, 2009.

[20] L. R. Harris and G. T. Brown, "Mixing interview and questionnaire methods: Practical problems in aligning data," Practical Assessment, Research, and Evaluation, vol. 15, no. 1, p. 1, 2010.

[21] L. Cohen, L. Manion, and K. Morrison, Research Methods in Education, routledge, 2007.

[22] E. M. Bakheet and A. M. Gravell, "Flipped classroom from computer science instructors' perspectives: A proposed model," in Proc. the 2019 8th International Conference on Educational and Information Technology, 2019, pp. 131-136.

[23] E. M. Bakheet and A. M. Gravell, "Investigating factors based on an extended UTAUT model to confirm computer science instructors' behavioural intention to adopt the flipped classroom," International Journal of Information and Education Technology, vol. 10, no. 10 2020.

[24] R. Likert, "A technique for the measurement of attitudes," Archives of Psychology, 1932.

Copyright (C) 2021 by the authors. This is an open access article distributed under the Creative Commons Attribution License which permits unrestricted use, distribution, and reproduction in any medium, provided the original work is properly cited ( $\underline{\text { C BY } 4.0)}$ ).

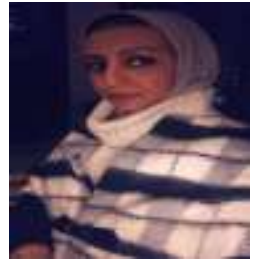

Eman Bakheet was born in Madinah, KSA. She studied the bachelor of information systems at Taibah University, KSA, and the master of information systems at Gannon University, USA. Currently, she is a computer science $\mathrm{PhD}$ candidate at the University of Southampton, UK.

She was a lecturer at Saudi electronic University and was the branch coordinator for the college of computing. Her research interests are but not limited to: e-learning, technology-enhanced learning, technology acceptance models, e-payments, online banking and system analysis and design.

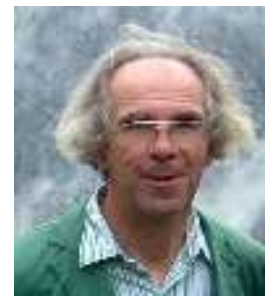

Andrew Gravell was born in 1956 in Exeter, UK. He studied maths and computer science at Cambridge. He worked as a software developer for 7 years, mostly at IBM's Hursley laboratory, working on a range of projects writing software for microprocessor-based systems.

In 1987 he joined ECS, Southampton, as a lecturer in computer science, and then as senior lecturer/associate professor / principal teaching fellow from 2002 onwards. He held the position Associate Dean for Education and the Student Experience, Faculty of Physical and Applied Sciences from 2010 to 2015. His research interests are Agile Software Development Methods, Computer Science Education and the Computer Science Pipeline.

Dr. Gravell is ECS senior tutor, timetabling owner, Computer Science Teaching Allocation, and chair of ECS Student Staff Liaison Committee. 